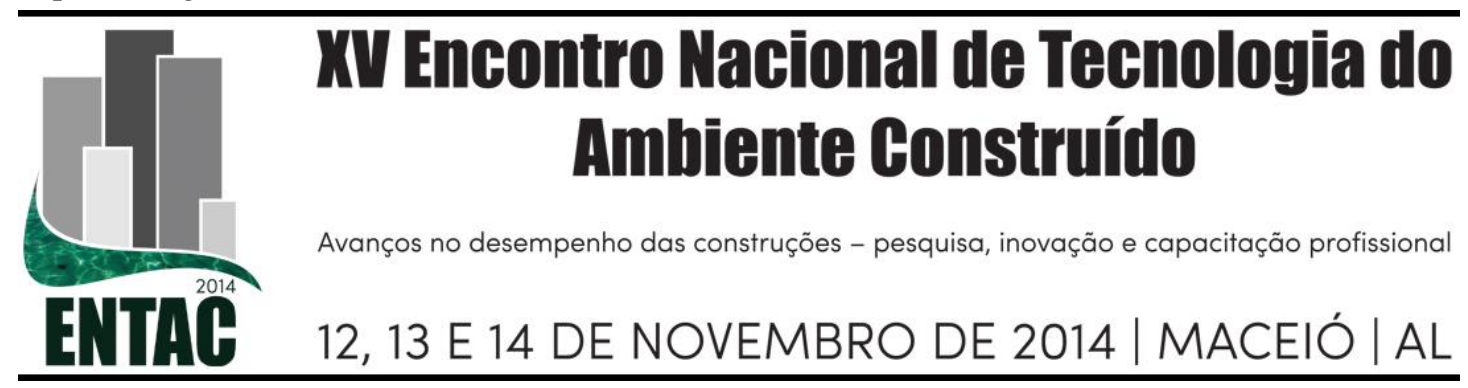

\title{
ESTUDO MULTICRITÉRIO APLICADO À HABITAÇÃO UNIFAMILIAR VERNÁCULA GUARANI
}

\author{
JIMÉNEZ, Marcelo Adolfo (1); BASTOS, Leopoldo Eurico Gonçalves (2)
}

(1) PROARQ/ Universidade Federal do Rio de Janeiro, e-mail: marcej27@gmail.com (2) PROARQ/

Universidade Federal do Rio de Janeiro, e-mail: leopoldobastos@gmail.com

\begin{abstract}
RESUMO
O presente trabalho visa analisar sob o enfoque bioclimático a tipologia de vivenda rural vernácula utilizada no Paraguai e na região guarani da América do Sul entre as bacias dos rios Paraguai e Paraná, sob a denominação de Culata Yovai. Procura-se verificar para esta tipologia como se dá a sua adequabilidade ao entorno climático-ambiental e ressaltar aspectos de interesse para possíveis releituras arquitetônicas de modo a garantir a imagem sócio-cultural e assim implementar caso necessário, melhorias em termos de materiais e processos construtivos para propiciar o conforto, qualidade ambiental e adequações funcionais. Como a região de estudo é fronteiriça ao Brasil pode-se utilizar no estudo as normas NBR 15220 e 6401. O intento é o de levantar subsídios para uma conciliação no projeto arquitetônico entre estratégias biclimáticas sem afetar o valor simbólico-cultural da forma.
\end{abstract}

Palavras-chave: Conforto ambiental, arquitetura vernácula, habitação popular.

\begin{abstract}
The aim of this work is to analyze under a bioclimatic approach a vernacular house typology encountered in Paraguay and inside the Guarani region comprised between Paraguay and Paraná basin rivers, known as Culata Yovai. It is tried to verify how this typology is responsive to the environmental-climatic conditions, and enlighten improvements, if is adequate in terms of materials, constructive processes, to propitiate comfort, environmental quality and functional adequacy. As this region is near the Brazilian frontier, the standards NB 15220 and 6401 are used. The intent is to contribute about a possible conciliation for architectonic projects of a bioclimatic approach with the social-cultural values of the form.
\end{abstract}

Keywords: Environmental comfort, vernacular architecture, low-income houses.

\section{INTRODUÇÃO}

É importante promover o debate sobre a importância dos estudos da arquitetura vernácula, hoje em dia e para o século XXI, não como um estudo de tradições passadas, mas como uma contribuição de novos métodos, soluções e realizações para o futuro ambiente construído. Não é recomendável uma cópia de certas qualidades formais como tetos, volumetrias, detalhes, etc., inspirada em uma visão romântica do vernáculo, já que existem muitos exemplos de soluções quase anticlimáticas, mas sim uma aproximação derivada das lições e princípios resultantes de estudos de ambientes vernáculos, e como estas lições são aplicadas no projeto, relacionadas ao clima, usos da energia, e noções de conforto ambiental. (FORSTER et al, 2006).

O nome do tipo de vivenda rural vernácula conhecida como "Culata Yovai" vem do idioma Guarani falado no Paraguai: Kuláta Jovái, onde kuláta significa em português: 
quarto, cômodo; e jóvai significa: confrontados, situados em frente, face a face, portanto a tradução correta é vivenda de "quartos confrontados". Consiste em uma construção simétrica, composta principalmente por três espaços colocados em linha e cobertos sob um mesmo teto. Os dois espaços extremos, "culatas", são fechados e relacionam-se entre si através do espaço central aberto. Este constitui um ambiente ventilado e sombreado para as atividades diárias dos moradores, em alguns casos conta com uma pérgula como prolongação do espaço central. A cozinha e a latrina ficam separadas do resto da casa. (Figuras 1 e 2)

\section{Figuras 1 e 2 - Exemplo de uma vivenda vernácula tipo Culata Yovai}
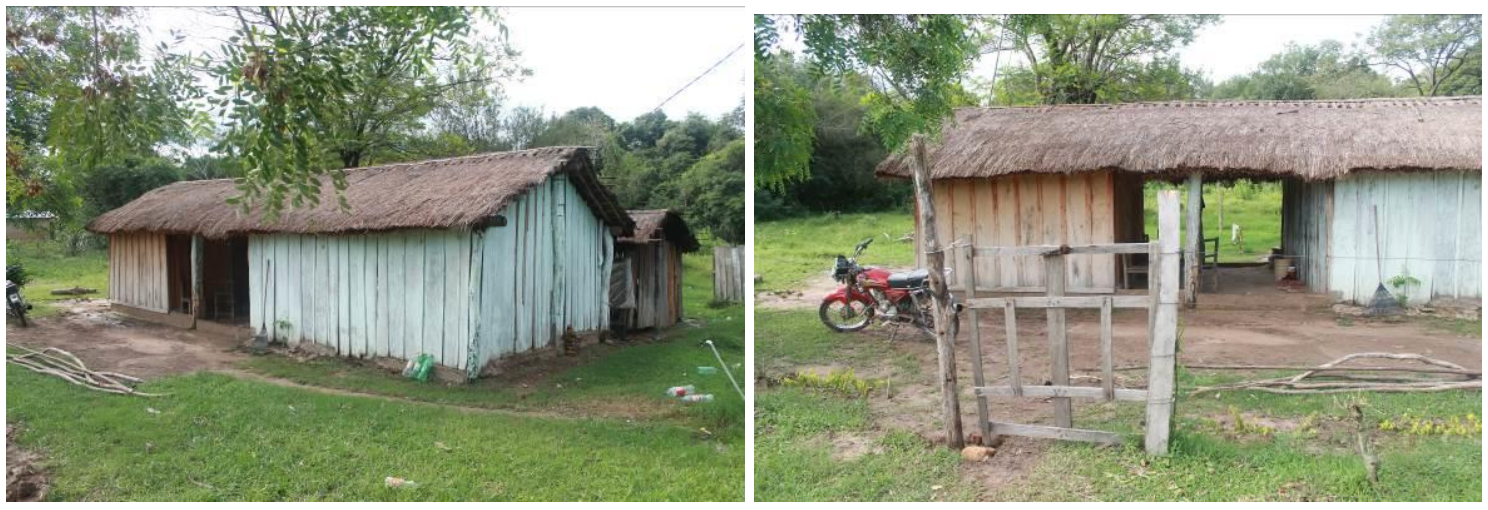

Fonte: Arquivo do autor (2014)

Para sua construção, ao início é feita a estrutura - esqueleto de madeira composta geralmente de troncos de mbocaja ou karanda'y para suporte do teto de kapi' $i$ ou palha, ou folhas de palma, o chão é de terra batida, e posteriormente são feitas as paredes, só como uma simples cobertura vertical com o material disponível no lugar. (SANCHEZ, 2011). Os materiais de construção das paredes e tetos variam de acordo com as diferentes zonas, como adobe, troncos de karanda'y e palha em áreas secas, pau a pique ou madeira com palha em áreas florestais, até tijolos e telhas cerâmicas perto de núcleos urbanos, pelo esgotamento de materiais de coleta. (HERREROS et al, 1984) Os três espaços da Culata Yovai estão geralmente modulados ainda de acordo aos lances, modulo estrutural-espacial utilizado durante o período colonial no Paraguai que correspondia ao comprimento dos troncos de madeira disponíveis, onde um lance equivale aproximadamente a $4 \mathrm{~m} \times 4 \mathrm{~m}$ em planta. (GIURIA, 1950). A construção é feita pelos mesmos moradores com uma grande economia de meios, obtendo assim poupança de trabalho e de materiais, mas procurando também certo grau de conforto e assim minimizar as condições do clima externo. Este esquema básico de vivenda, de formas puras e simples, se mantém até hoje, nas regiões rurais de clima subtropical úmido das bacias dos rios Paraná e Paraguai, com diversos materiais e com variantes em sua organização de planta, sendo uma resposta muito válida do ponto de vista climático e cultural

No contexto atual de procura de soluções sustentáveis e bioclimáticas para a habitação de interesse social, aparece como uma alternativa a releitura desta arquitetura vernácula. Em grande parte esquecida pelos arquitetos, esta tipologia é agora incorporada por alguns programas de habitação de interesse social, principalmente no Paraguai e na Argentina, para projetos de casas populares nos meios rural e suburbano. Procura-se 
agregar um valor bioclimático e ao tempo simbólico-cultural, considerando que geralmente os usuários finais são provenientes do campo.

Conciliar num projeto os valores bioclimáticos sem afetar o valor simbólico-cultural da forma requer uma análise do comportamento climático da arquitetura que permita avaliar que aspectos podem mudar ou serem melhorados para alcançar o conforto ambiental em sentido amplo.

Este trabalho tem como objetivo avaliar o tipo de vivenda rural vernácula Culata Yovai em relação a seu entorno climático, para identificar estratégias de projeto a serem aplicadas em novas releituras desta tipologia na vivenda de interesse social da região na procura de conforto ambiental.

\section{FUNDAMENTAÇÃO}

\subsection{O contexto climático}

As regiões de clima subtropical úmido, identificadas como Cfa ou Cwa na classificação Köppen (PEEL et al, 2007) se caracterizam por verões quentes e úmidos e invernos frios, com chuvas fortes em áreas costeiras, que diminuem por um inverno cada vez mais seco com o aumento da distância à costa. Na América do Sul é conhecido como clima pampeano e ocorre no nordeste da Argentina, Uruguai, sul do Brasil e leste do Paraguai. É um clima complexo do ponto de vista do projetista, onde para estabelecer os requisitos de projeto evidentemente deve estabelecer uma solução arquitetônica de compromisso. (KONYA, 1981).

Como ainda não há normas específicas para bioclimatismo no Paraguai, são adotadas as normas brasileiras do sitio brasileiro mais próximo aos sítios de estudo em território paraguaio, devido as semelhanças das características climáticas da região com o clima subtropical úmido (PEEL et al, 2007), para realizar uma avaliação do desempenho climático das vivendas. É adotado o Zoneamento Bioclimático Brasileiro da Norma ABNT - NBR 15220 de desempenho térmico de edificações, pelo conjunto de recomendações e estratégias construtivas, embora sejam destinadas para habitação unifamiliar de interesse social, podem ser aplicadas perfeitamente para esta vivenda vernácula unifamiliar rural.

\section{MÉTODO}

É uma Pesquisa documental, que inclui levantamento e estudo de caso

Primeiramente com base em referências bibliográficas, e pesquisas de campo, é feito um levantamento das características arquitetônicas e construtivas da tipologia, sua implantação e compatibilidade com as condições climáticas e culturais. Entrevistas com moradores para redigir um inventário de seus gostos e preferências (ideia de conforto).

A seguir são identificados os sítios de implantação, com detalhes de insolações, ventos e rugosidades de vegetação e solo, com levantamento de dados físicos e meteorológicos do local em sua proximidade. Utilizou-se os dados climáticos da Dirección Nacional de Aeronáutica Civil del Paraguay - Dirección de Meteorología e Hidrología - Estação de Coronel Oviedo, que é a mais próxima da região estudada.

Com a informação coletada desenvolveu-se um modelo virtual genérico de Culata Yovai para analisar suas características, fazendo uma confrontação com as diretrizes construtivas da Zona Bioclimática 3 da norma NBR 15220, e com o subsidio de cálculos e simulações computacionais, determinou-se seu grau de adequação climática. 
Para o cálculo de apoio utilizou-se os coeficientes de pressão nas superfícies da casa e ao valor da velocidade dada pela meteorologia é aplicado o perfil de velocidade logarítmico (ALLARD et al, 1998, através da seguinte equação:

Onde:

$$
\mathrm{Vh}=\mathrm{Vm} \cdot \Lambda(\mathrm{zo}) \cdot \ln (\mathrm{h} / \mathrm{zo})
$$

$\mathrm{h}=$ altura da casa $(=2,3 \mathrm{~m})$;

$\mathrm{Vm}=$ velocidade média provida pela estação meteorológica a $10 \mathrm{~m}$ de altura, $(=5,03 \mathrm{~m} / \mathrm{s})$;

zo $=$ rugosidade do terreno $(=0,25)$;

$\Lambda($ zo $)$ : coeficiente dependente do tipo de terreno $(=0.21)$.

A vazão $\mathrm{Q}\left(\mathrm{m}^{3} / \mathrm{s}\right)$ no interior do espaço aberto central pode ser obtida a partir da equação empírica (2):

$$
\mathrm{Q}=\mathrm{Cd} . \mathrm{S} . \mathrm{Vh}[(\mathrm{Cp} 1-\mathrm{Cp} 2)]^{1 / 2}
$$

Onde:

A1, A2: áreas iguais de aberturas: corredor $(4 \times 2,3) \mathrm{m}^{2}$; e janelas $(0,9 \times 1,0) \mathrm{m}^{2}$;

$\mathrm{Cd}$ : fator de infiltração $(=0,6)$;

Cp1, Cp2: coeficientes de pressão média nas fachadas opostas $(+0.7)$ e $(-0.25)$, conforme CSTB, (Fauconnier, 1988);

$\mathrm{S}$ : calculado por $\left(1 / \mathrm{S}^{2}=1 / \mathrm{A} 1^{2}+1 / \mathrm{A} 2^{2}\right)$.

Confrontando estes cálculos de vazões com aquelas necessárias para arrefecer os três ambientes devido às cargas térmicas de origem solar, é possível verificar se a vazão potencial de ventilação natural nestes ambientes poderá estabelecer condições de conforto térmico para seus usuários, pela norma NBR 6401. Para esse fim, a irradiação solar no envelope é obtida por meio de simulações com o software RADLITE, (CASTRO et al, 2002).

Para complementar foi realizada uma avaliação das condições de iluminação natural utilizando os valores mínimos aceitáveis da norma NBR 5413 de Iluminação de interiores / especificação 1982. Os níveis de iluminação natural no interior dos dois quartos são obtidos para os meses de janeiro e julho por meio de simulações com o mesmo software RADLITE.

Finalmente são determinadas estratégias de projeto a serem aplicadas em novas releituras desta tipologia na vivenda de interesse social da região.

\section{RESULTADOS E DISCUSSÃO}

\subsection{Estudo de caso}

Considera-se a partir do levantamento de campo realizado, um estudo de caso: habitação rural unifamiliar tipo Culata Yovai localizada no Paraguai, departamento de Paraguarí, na localidade de Yvytymí, com as seguintes coordenadas: $25^{\circ} 44$ '58,31" (latitude), 56 48'10,11" (longitude), $134 \mathrm{msnm}$ (altitude), num terreno com declividade insignificante e uma cobertura vegetal rasteira. (Figuras 3 e 4). O mês mais quente e Janeiro, com uma temperatura média máxima de $33,3{ }^{\circ} \mathrm{C}$, e o mês mais frio e Julho, 
com uma temperatura média mínima de $10,5^{\circ} \mathrm{C}$. Os ventos predominantes na região no mês de Janeiro são NNE $\left(22,5^{\circ}\right)$, com velocidade média de $18,1 \mathrm{Km} / \mathrm{h}=5,03 \mathrm{~m} / \mathrm{s}$, e os ventos de frios de chuva são do Sul $\left(270^{\circ}\right)$ com velocidade média de $23,6 \mathrm{Km} / \mathrm{h}=6,55$ $\mathrm{m} / \mathrm{s}$

Figuras 3 e 4 - Mapa de localização e sitio de implantação do estudo de caso
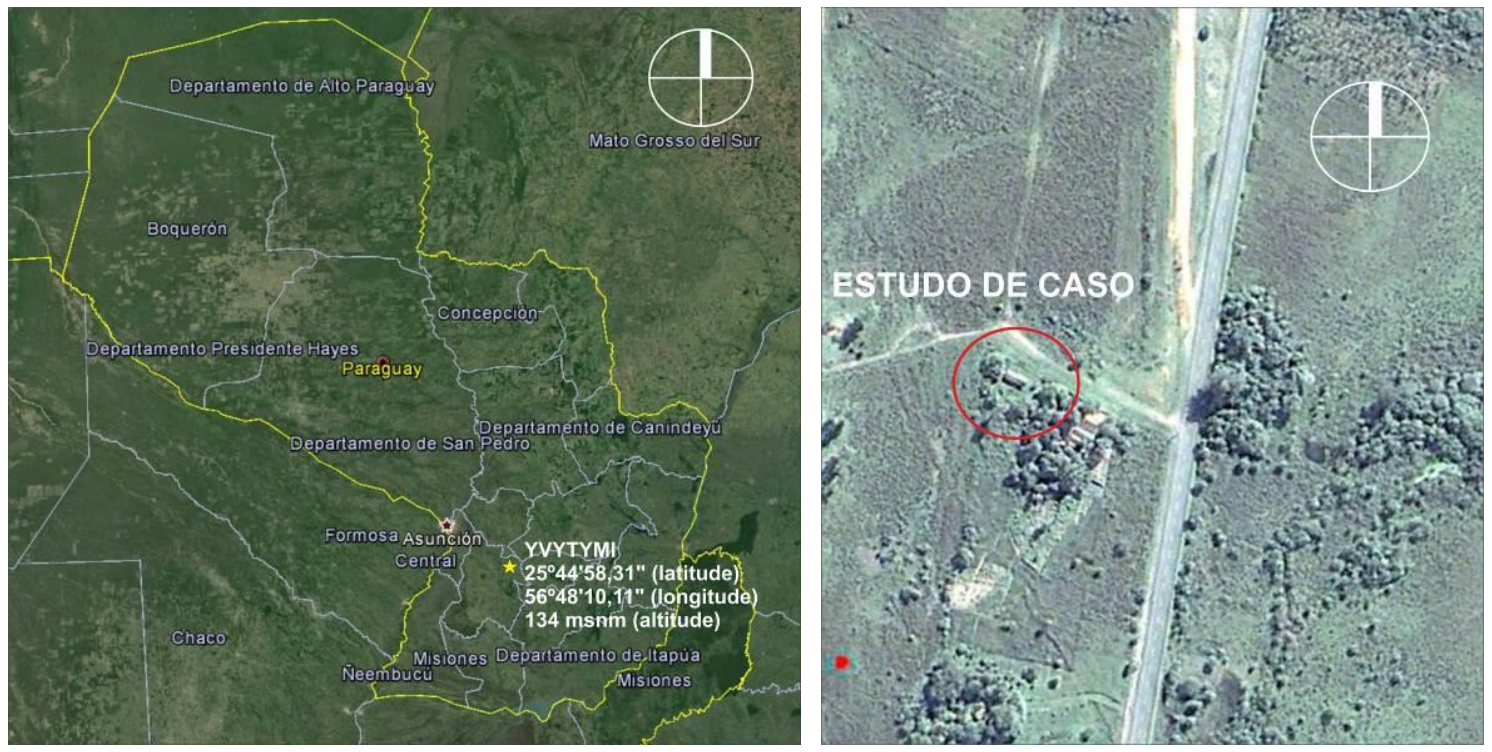

Fonte: Google Earth (2014)

A vivenda conta com três espaços com a modulação característica de $4 \mathrm{~m}$ x $4 \mathrm{~m}$ em planta para cada espaço, a altura de apoio do teto na parede é $2,3 \mathrm{~m}$, e o teto com duas águas tem uma inclinação de $60 \%$. Os quartos situados nas extremidades da casa (ambiente 1 e 3) são espaços multiuso preferentemente destinados a dormitórios coletivos, cada um deles possui uma janela na fachada NE de dimensões $0,9 \mathrm{~m} \times 1,00 \mathrm{~m}$ e uma porta de acesso ao espaço central, de $0,8 \mathrm{~m} \times 2,00 \mathrm{~m}$. O espaço central aberto também é de uso múltiplo, se destina para as atividades diárias dos moradores em geral. A cozinha e a latrina são espaços separados da casa. O teto de palha é suportado por uma estrutura de pilares e vigas de madeira, e as paredes são de tábuas de madeira que não têm função de suportar o teto. As aberturas são também de madeira. (Figuras 5 e 6 )

As diretrizes da Zona Bioclimática 3, levam em consideração o tamanho das aberturas para ventilação, a proteção das aberturas, as vedações externas (tipo de parede e tipo de cobertura), e as seguintes estratégias de condicionamento térmico passivo (NBR 15220, 2003) 
Figura 5 - Vista da fachada frontal

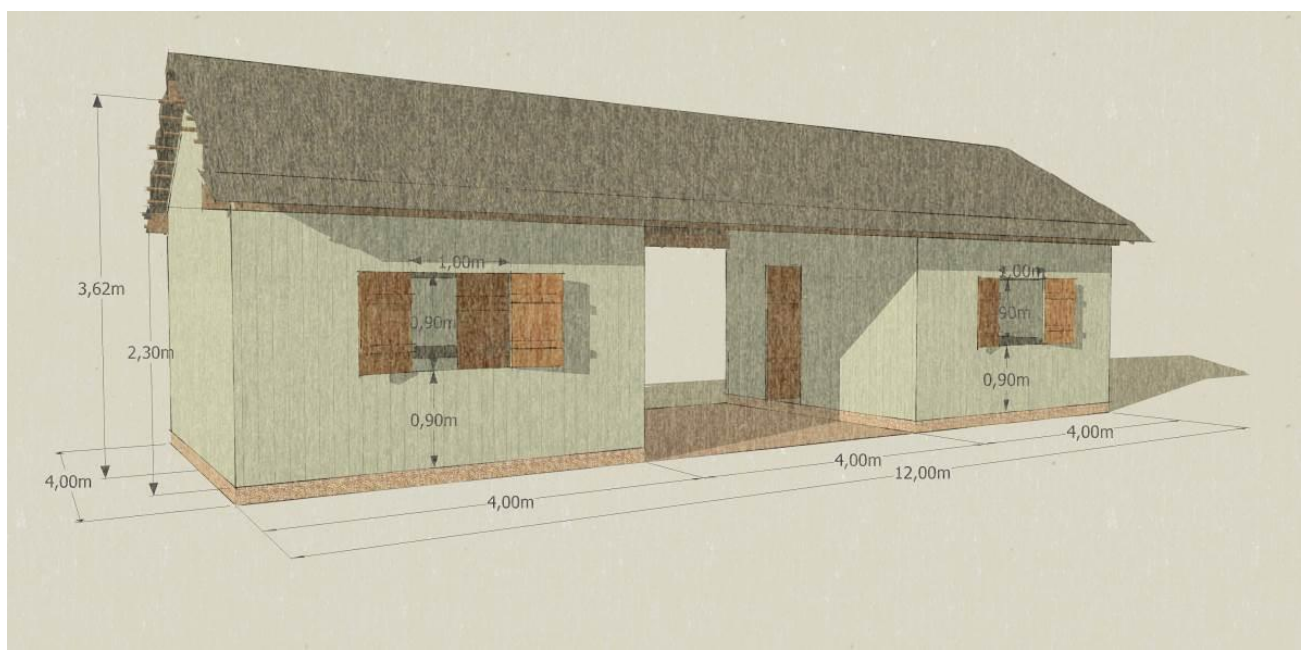

Fonte: Elaboração própria (2014)

Figura 6 - Fachada, corte e planta arquitetônicas

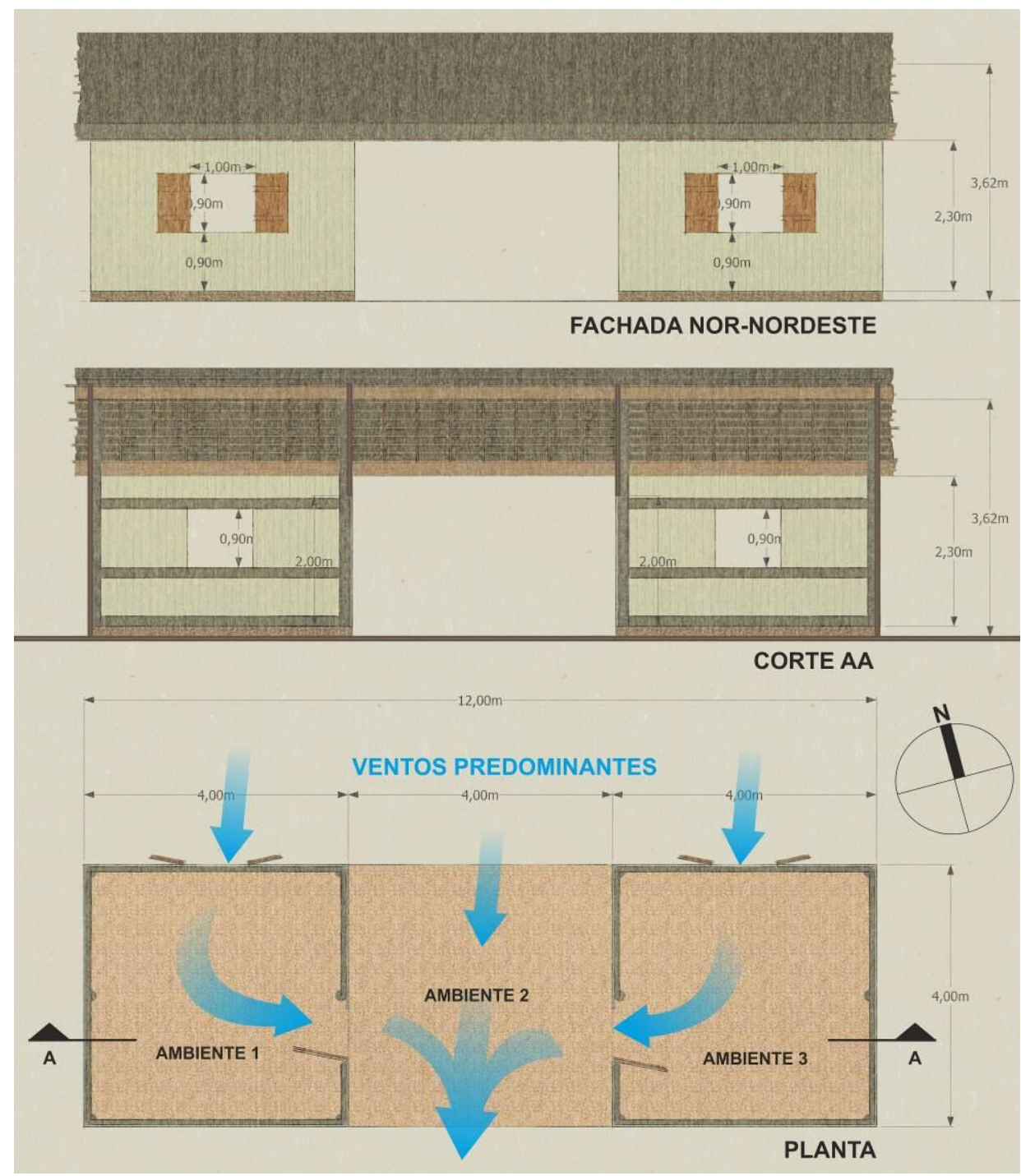

Fonte: Elaboração própria (2014) 


\subsection{Confrontação das características encontradas no caso de estudo com as diretrizes construtivas para a Zona Bioclimática 3}

$\mathrm{Na}$ carta bioclimática representativa para a Zona Bioclimática 3 (Figuras 7 e 8) é possível ver que os registros abarcam as seguintes zonas de conforto térmico, com suas respectivas estratégias de condicionamento térmico passivo:

Figuras 7 e 8 - Zona bioclimática 3, e Carta bioclimática apresentando as normais climatológicas de cidades desta zona
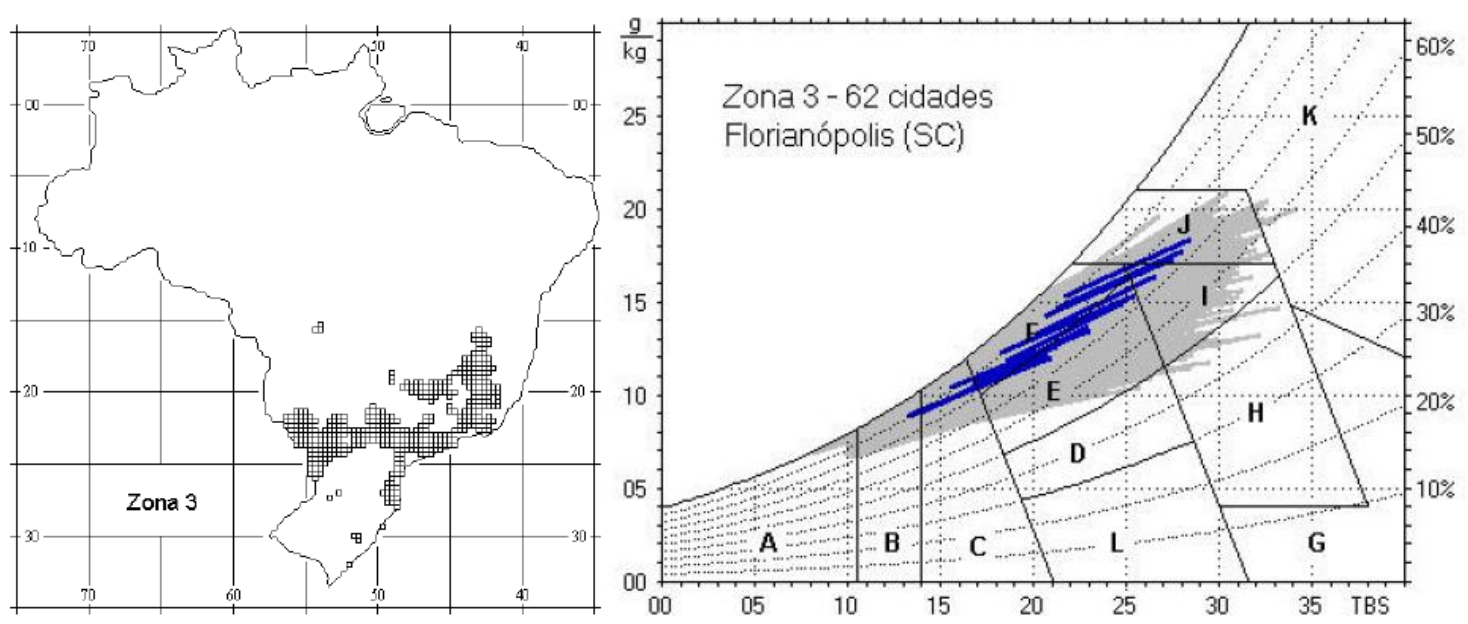

Fonte: NBR 15220 (2014)

\section{Maior incidência no verão:}

I e J - Zona de ventilação. A orientação do espaço aberto central, responde ao conhecimento empírico das condições climáticas, o espaço central fica orientado aos ventos dominantes da região na direção NNE. A ventilação cruzada é obtida nos ambientes 1 e 3, só quando a porta de acesso é mantida aberta, já que cada ambiente conta com uma soa janela orientada à direção predominante dos ventos NNE, e as outras paredes ficam fechadas para se proteger dos ventos fortes de chuva provindos do Sul. Com essas condições e utilizando a equação 1 , a vazão por ventilação natural determinada para o ambiente 2 (espaço central aberto) é de $8,74 \mathrm{~m}^{3} / \mathrm{s}$, enquanto aquelas para os ambientes 1 e 3 (quartos dos extremos) igualam a $2,18 \mathrm{~m}^{3} / \mathrm{s}$. Estes valores de vazões obtidas para os ambientes 1,2 e 3 são superiores à aqueles necessários para retirar o calor dos ambientes (de origem solar), sendo $0,19 \mathrm{~m}^{3} / \mathrm{s}$ para o ambiente 2 (espaço central aberto); $0,32 \mathrm{~m}^{3} / \mathrm{s}$ para o ambiente 1 , e igual a $0,33 \mathrm{~m}^{3} / \mathrm{s}$ para $\mathrm{o}$ ambiente 3. Na situação invernal, a vazão por infiltração nos ambientes 1 e 3 é de 0,069 $\mathrm{m}^{3} / \mathrm{s}$ para vento Sul, também superior aos valores estabelecidos pela Norma NBR 6401 para uma taxa de renovação mínima exigida por ambiente.

Em caso de ampliação da vivenda, geralmente é edificada uma nova construção idêntica à anterior adjacente a ela, de forma que o novo espaço central coincide com o antigo, deste modo se vai gerando um "canal central de ventilação", instrumento de considerável valor nos quentes verões do subtrópico.

F- Zona de desumidificação (renovação do ar). Estas estratégia é obtida através da renovação do ar interno por ar externo através da ventilação dos ambientes Nos meses mais quentes, com alto percentual de umidade, onde o conforto térmico resulta de uma adequada proteção de sombras mais uma boa ventilação natural, o espaço central pode satisfazer às duas necessidades. Neste espaço central a proteção aos ventos, de chuva e 
ao frio invernal resulta muito simples com a colocação em alguns casos de uma cobertura móvel. (HERREROS et al, 1984; CARLI, 1987).

\section{Maior incidência no inverno:}

C - Zona de massa térmica para aquecimento. As quedas bruscas de temperatura originadas pelos ventos do Sul, obrigam ao uso dos espaços fechados como as culatas ou quartos, onde pode se estabilizar a temperatura interna dependendo do material da cobertura. No caso do estudo é utilizada a madeira, mas no levantamento verificou-se que é muito comum a utilização do pau-a-pique, que consiste em construir uma estrutura em tramas de taquaras, sobre as quais vai uma capa de barro de espessura variável, sendo este pouco sensível as variações de temperatura, vai proporcionar um ambiente confortável, fresco no verão e abrigado no inverno (GIURIA, 1950).

B - Zona de aquecimento solar da edificação.

A forma, a orientação e a implantação da edificação, estão pensadas mais para os períodos quentes que são mais prolongados que os frios, a orientação Norte - Sul é favorável a menor penetração solar no verão, ficando as fachadas Leste - Oeste protegendo o espaço central contra a radiação direta, portanto não contribui muito para otimizar o aquecimento no período frio. A cor externa dos componentes é a dos próprios materiais de construção, em poucos casos utilizam tintas claras, novamente pensando mais no período quente que o frio.

\section{Menor incidência no verão:}

H e I - Zona de massa térmica de refrigeração. O pau-a-pique, segundo a espessura da capa de barro vai estabilizar as variações de temperatura no interior.

K - Zona de refrigeração artificial. Os exemplos levantados não têm sistemas mecânicos de resfriamento artificial.

\section{Menor incidência no inverno:}

A - Zona de aquecimento artificial. Os exemplos levantados não apresentam sistemas mecânicos de aquecimento artificial (calefação).

\section{Também devem ser atendidas as seguintes diretrizes:}

Com relação as vedações externas em paredes e coberturas, os materiais de construção típicos são aqueles recursos naturais disponíveis do lugar, portanto, apresentam um comportamento adequado ante as exigências do clima e contribuem ao condicionamento natural. Nos casos levantados há principalmente construções em madeira, taquaras com barro nas paredes e palha na cobertura.

Aberturas para ventilação: medias ( $15 \%$ da área do piso $<\mathrm{A}<25 \%$ da área do piso). $\mathrm{A}$ área da abertura do caso de estudo é de $0,9 \mathrm{~m}^{2}$, ou seja, menor que o requerido no caso $2,4 \mathrm{~m}^{2}$ (15\% da área do piso), portanto pela norma seria recomendável um aumento das mesmas. Entretanto, observa-se que o efeito Venturi produzido na parte central da edificação provoca uma sucção nas portas de comunicação com os dois quartos, o que vem favorecer o estabelecimento de valores adequados de vazões no verão.

Sombreamento das aberturas e permitir sol durante o inverno. Nos exemplos levantados, a vivenda geralmente está implantada de acordo a vegetação circundante, com a finalidade de relacionar os espaços sombreados exteriores com os criados pela própria edificação. 
Finalmente considera-se a distribuição do nível de luz natural num ponto central do ambiente, a uma altura de $0,75 \mathrm{~m}$ do chão. Os cálculos são determinados de acordo com as dimensões e esquadrias das janelas existentes, e dentro do horário de luz diurna, já que como são espaços multiuso, não têm um horário de ocupação fixo. No mês de Janeiro, o período onde é atingido o nível requerido de iluminância de 200 lux se situa de 8:00 h às 17:30 h com céu claro, enquanto para uma condição de céu médio, somente de 10:00 h às 14:00h. Em Julho, o período onde é atingido o nível requerido de iluminância é de 7:45 h às 17:30h com céu claro, enquanto com céu médio é de 9:00h às 16:30h. Com céu encoberto esses níveis não são atingidos em nenhum momento.

\section{CONSIDERAÇÕES FINAIS}

Os arquitetos, ao realizarem novas releituras desta tipologia para habitação de interesse social para esta região bioclimática, devem manter a intenção de conciliar os valores bioclimáticos sem afetar o valor simbólico-cultural da forma. Portanto, é importante manter o esquema "binuclear" de composição, dos três corpos, com os extremos fechados e o central aberto. Porém, devem ser utilizadas para possíveis extensões, coberturas leves e móveis que regulem a continuidade espacial e visual garantindo a ventilação natural, para que o espaço central continue como um espaço de reunião multiuso, e ao mesmo tempo seja adequado às necessidades de privacidade da vida quando for o caso de uma implantação da edificação no entorno urbano.

Para a ventilação natural durante o verão, é importante manter a característica orientação do espaço central com relação aos ventos predominantes, e a colocação estratégica de novas aberturas nos quartos fechados para garantir uma ventilação cruzada.

Os níveis de ventilação e iluminação natural podem ser melhorados nestes ambientes com o aumento das aberturas e a colocação nestas, de dispositivos flexíveis de controle dos ventos e da radiação solar de acordo as necessidades do verão e do inverno. $\mathrm{O}$ desenho flexível é importante neste clima.

Em alguns momentos do ano poderá ser necessário o uso de arrefecimento artificial para amenizar a eventual sensação de desconforto térmico por calor, e no inverno o uso de aquecimento artificial (calefação) para amenizar a eventual sensação de desconforto térmico por frio.

É necessária a incorporação de instalações prediais para sua adaptação ao estilo de vida moderno, como a incorporação da cozinha e o banheiro dentro da habitação de acordo as normas estabelecidas.

Os materiais e as técnicas construtivas utilizadas estão de acordo as exigências climáticas da região. Porém, deveriam ser contemplados em novas construções novos materiais e técnicas industriais que devem garantir ou melhorar as condições dadas pelo modelo vernáculo. Ou seja, observar também as condições de salubridade da edificação face aos problemas das endemias rurais.

Contemplar futuras ampliações da habitação que não desvirtuem a leitura da tipologia tradicional e suas características bioclimáticas, de modo a favorecer a incorporação de novos espaços sombreados e ventilados. 


\section{AGRADECIMENTOS}

A CAPES e ao CNPq pelos apoios recebidos.

\section{REFERÊNCIAS}

ABNT - Associação Brasileira de Normas Técnicas. NBR 15220. Desempenho térmico de edificações. Parte 3: Zoneamento bioclimático brasileiro e diretrizes construtivas para habitações unifamiliares de interesse social. Rio de Janeiro. 2003.

ABNT - Associação Brasileira de Normas Técnicas. NBR 5413. Iluminação de interiores. Rio de Janeiro. 1982.

ABNT - Associação Brasileira de Normas Técnicas. NBR 6401. Instalações centrais de arcondicionado para conforto -Parâmetros básicos de projeto. Rio de Janeiro. 1978.

ALLARD, F. et al. Natural ventilation in buildings. London. Editor James\&James. 1998.

CASTRO, E. B. P.; VIRGONE, J.; BASTOS, L. E. G. Étude Paramétrique du Comportement Énergétique et Lumineux d'un Bâtiment en Climat Tropical Humide. In : Proceedings of IBPSA France. 2002. Paris. CD-ROM, p.64-70.

FAUCONNIER, R. Énergétique des Bâtiments. Bilan d’air tenant compte de I'hulidité, des ouvrants et des infiltrations. Paris. ADEME. PYC Édition. 1988. p. 71-90.

FORSTER, W.; HEAL, A.; PARADISE, C. The vernacular as a model for sustainable design. In: PLEA Conference on Passive and Low Energy Architecture, 23., 6-8 September 2006, Geneva, Switzerland.

GIURIA, J. Arquitectura en Paraguay. Buenos Aires. Universidad de Buenos Aires. Facultad de Arquitectura y Urbanismo. 1950.

HERREROS, A., et al. La culata yovai. Asunción. Centro paraguayo de estudios sociológicos. 1984.

KONYA, A. Diseño en climas cálidos. Manual práctico. Primera edición española. Madrid. H. Blume Ediciones. 1981.

PEEL, M. C.; FINLAYSON, B. L.; MCMAHON, T. A. Updated world map of the KöppenGeiger climate classification. Disponível em: $<$ http://www.hydrol-earth-systsci.net/11/1633/2007/hess-11-1633-2007.html>. Acesso em: 11 mai. 2014.

SÁNCHEZ, D. D. Optimización, aplicación y mantenimiento en la construcción de viviendas, con el uso de karanda'y en el Chaco Paraguayo: caso Ex Obraje Ceibo, distrito de Puerto Pinasco, Pte. Hayes. Trabajo Final de Grado. San Lorenzo. Universidad Nacional de Asunción - Facultad de Arquitectura. 2011. 